\title{
Correction to: Methylcyclohexane Continuous Distillation Column Fault Detection Using Stationary Wavelet Transform and K-Means
}

Hanae Azzaoui, Imad Manssouri, and Bachir Elkihel

\section{Correction to:}

Chapter "Methylcyclohexane Continuous Distillation Column Fault Detection Using Stationary Wavelet Transform and K-Means" in: B. Hajji et al. (Eds.): Proceedings of the 1st International Conference on Electronic Engineering and Renewable Energy, LNEE 519, https://doi.org/10.1007/978-981-13-1405-6_48

The original version of the paper was published with wrong author name "Imad Mansouri". This has now been corrected to "Imad Manssouri". 